Supplement of Ocean Sci., 16, 593-614, 2020

https://doi.org/10.5194/os-16-593-2020-supplement

(C) Author(s) 2020. This work is distributed under

the Creative Commons Attribution 4.0 License.

(c) (1)

Supplement of

\title{
Spatiotemporal variability of light attenuation and net ecosystem metabolism in a back-barrier estuary
}

Neil K. Ganju et al.

Correspondence to: Neil K. Ganju (nganju@usgs.gov)

The copyright of individual parts of the supplement might differ from the CC BY 4.0 License. 


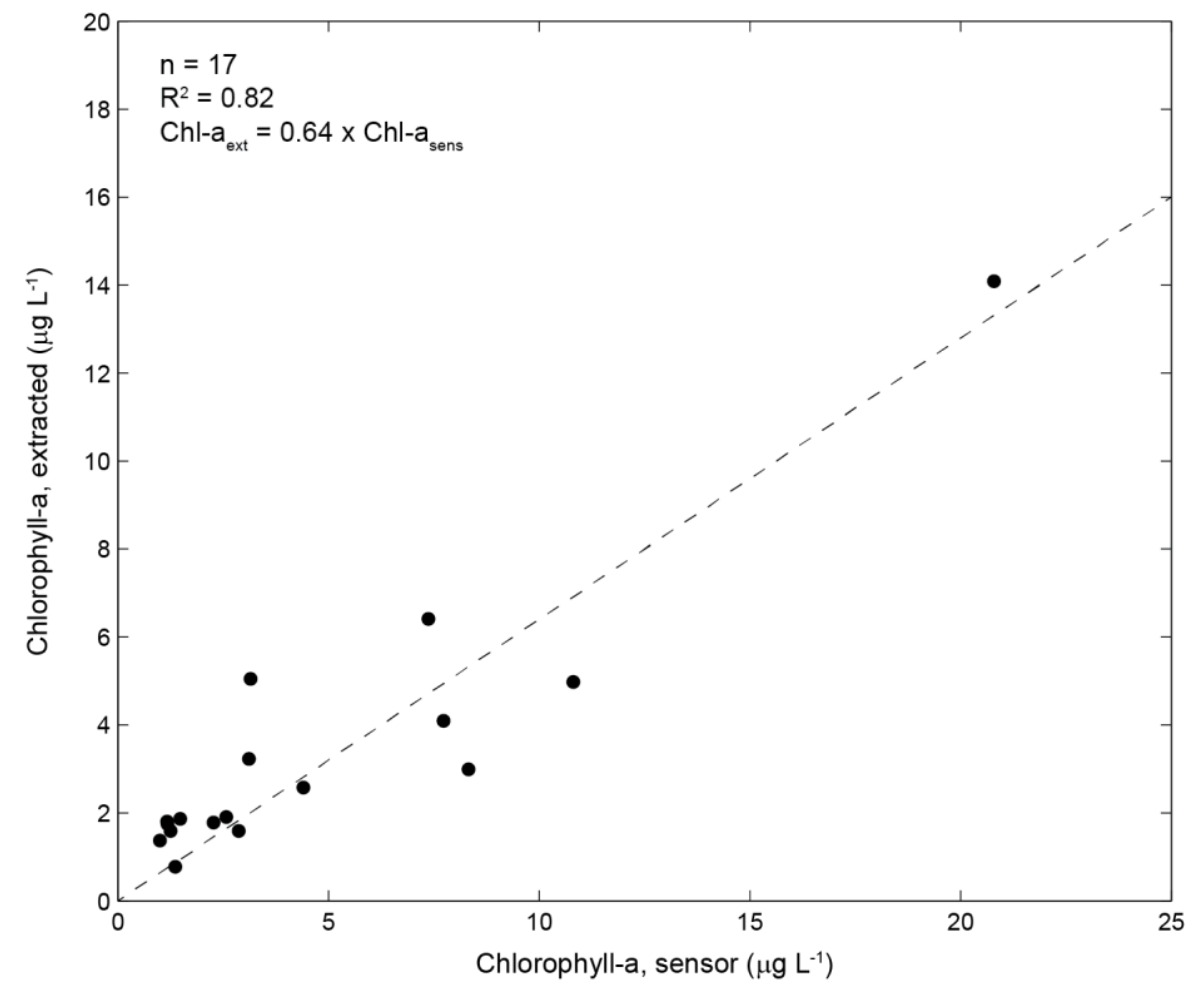

Supplementary Figure 1: Calibration of fluorescence-based chlorophyll-a to laboratory-measured, extraction-based chlorophyll-a. 


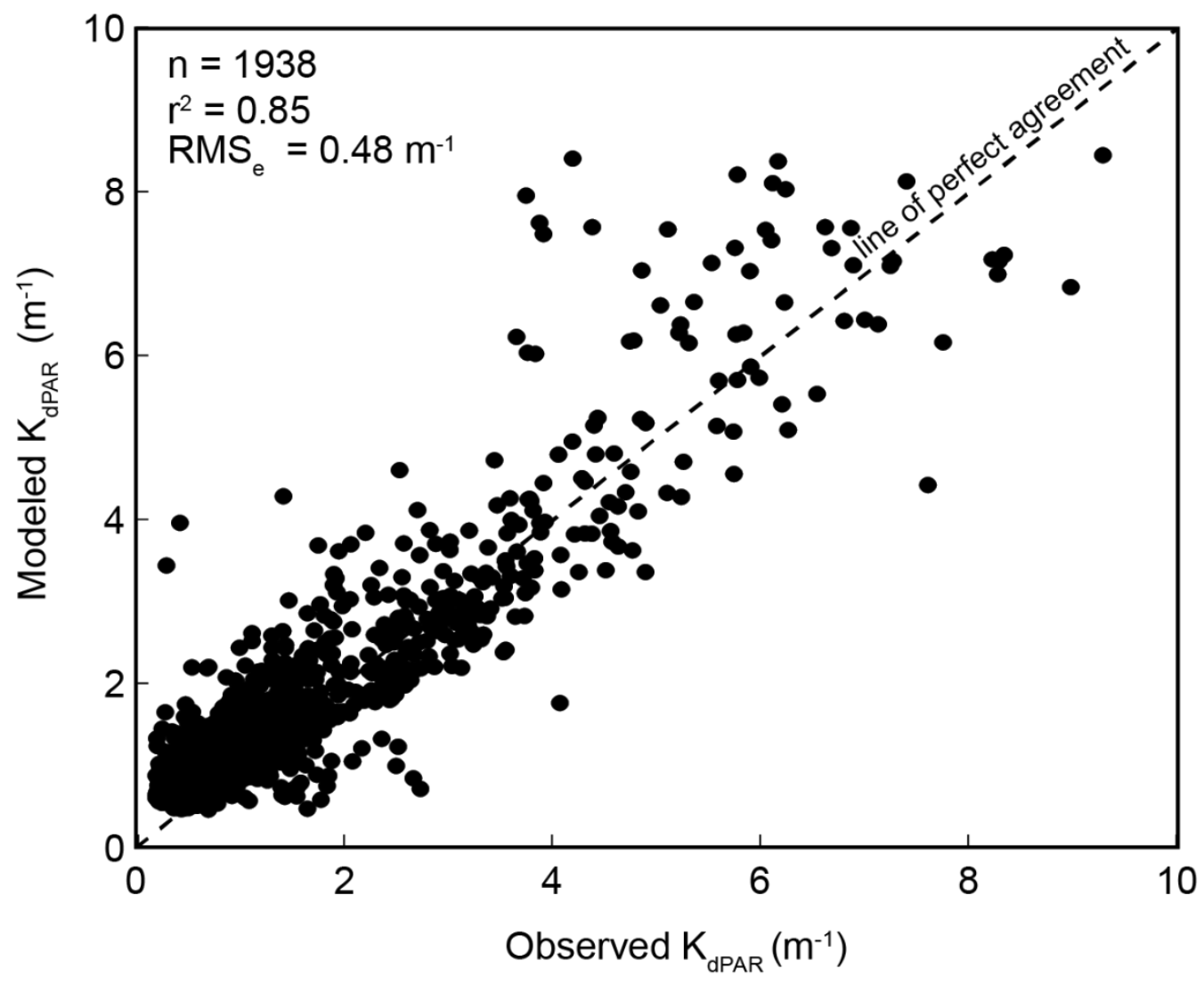

Supplementary Figure 2: Light model assessment, using 30 min averaged values. 